\title{
Antihypertensive Effects of Gynura divaricata (L.) DC in Rats with Renovascular Hypertension
}

\author{
Mi Hyeon Hong ${ }^{1,2}$, Xian Jun Jin ${ }^{1}$, Jung Joo Yoon ${ }^{1,2}$, Yun Jung Lee ${ }^{1,2} \oplus$, Hyun Cheol Oh ${ }^{3}$, \\ Ho Sub Lee ${ }^{1,2}$, Hye Yoom Kim ${ }^{1,2, *}$ and Dae Gill Kang 1,2,* \\ 1 College of Oriental Medicine and Professional Graduate School of Oriental Medicine, Wonkwang University, \\ Iksan, Jeonbuk 54538, Korea; mihyeon123@naver.com (M.H.H.); chinacross2013@hotmail.com (X.J.J.); \\ mora16@naver.com (J.J.Y.); shrons@wku.ac.kr (Y.J.L.); host@wku.ac.kr (H.S.L.) \\ 2 Hanbang Cardio-renal Research Center \& Professional Graduate School of Oriental Medicine, \\ Wonkwang University, Iksan, Jeonbuk 54538, Korea \\ 3 College of Pharmacy, Wonkwang University, Iksan 54538, Korea; hoh@wku.ac.kr \\ * Correspondence: hyeyoomc@naver.com (H.Y.K.); dgkang@wku.ac.kr (D.G.K.)
}

Received: 17 September 2020; Accepted: 22 October 2020; Published: 29 October 2020

Abstract: Gynura divaricata (L.) DC (Compositae) (GD) could be found in various parts of Asia. It has been used as a traditional medicine to treat diabetes, high blood pressure, and other diseases, but its effects have not yet been scientifically confirmed. Therefore, we aimed at determining whether GD could affect renal function regulation, blood pressure, and the renin-angiotensin-aldosterone system (RAAS). Cardio-renal syndrome (CRS) is a disease caused by the interaction between the kidney and the cardiovascular system, where the acute or chronic dysfunction in one organ might induce acute or chronic dysfunction of the other. This study investigated whether GD could improve cardio-renal mutual in CRS type 4 model animals, two-kidney one-clip (2K1C) renal hypertensive rats. The experiments were performed on the following six experimental groups: control rats (CONT); $2 \mathrm{~K} 1 \mathrm{C}$ rats (negative control); OMT (Olmetec, $10 \mathrm{mg} / \mathrm{kg} /$ day)-treated $2 \mathrm{~K} 1 \mathrm{C}$ rats (positive control); and $2 \mathrm{~K} 1 \mathrm{C}$ rats treated with GD extracts in three different doses (50, 100, and $200 \mathrm{mg} / \mathrm{kg} / \mathrm{day}$ ) for three weeks by oral intake. Each group consisted of 10 rats. We measured the systolic blood pressure weekly using the tail-cuff method. Urine was also individually collected from the metabolic cage to investigate the effect of GD on the kidney function, monitoring urine volume, electrolyte, osmotic pressure, and creatinine levels from the collected urine. We observed that kidney weight and urine volume, which would both display typically increased values in non-treated 2K1C animals, significantly decreased following the GD treatment ( ${ }^{\# \#} p<0.001$ vs. 2K1C). Osmolality and electrolytes were measured in the urine to determine how renal excretory function, which is reduced in $2 \mathrm{~K} 1 \mathrm{C}$ rats, could be affected. We found that the GD treatment improved renal excretory function. Moreover, using periodic acid-Schiff staining, we confirmed that the GD treatment significantly reduced fibrosis, which is typically increased in $2 \mathrm{~K} 1 \mathrm{C}$ rats. Thus, we confirmed that the GD treatment improved kidney function in $2 \mathrm{~K} 1 \mathrm{C}$ rats. Meanwhile, we conducted blood pressure and vascular relaxation studies to determine if the GD treatment could improve cardiovascular function in $2 \mathrm{~K} 1 \mathrm{C}$ rats. The heart weight percentages of the left atrium and ventricle were significantly lower in GD-treated 2K1C rats than in non-treated $2 \mathrm{~K} 1 \mathrm{C}$ rats. These results showed that GD treatment reduced cardiac hypertrophy in $2 \mathrm{~K} 1 \mathrm{C}$ rats. Furthermore, the acetylcholine-, sodium nitroprusside-, and atrial natriuretic peptide-mediated reduction of vasodilation in $2 \mathrm{~K} 1 \mathrm{C}$ rat aortic rings was also ameliorated by GD treatment (GD $200 \mathrm{mg} / \mathrm{kg} /$ day; $p<0.01, p<0.05$, and $p<0.05 \mathrm{vs}$. $2 \mathrm{~K} 1 \mathrm{C}$ for vasodilation percentage in case of each compound). The mRNA expression in the $2 \mathrm{~K} 1 \mathrm{C}$ rat heart tissue showed that the GD treatment reduced brain-type natriuretic peptide and troponin T levels $(p<0.001$ and $p<0.001$ vs. 2K1C). In conclusion, this study showed that GD improved the cardiovascular and renal dysfunction observed in an innovative hypertension model, highlighting the potential of GD as a therapeutic agent for hypertension. These findings indicate that GD shows beneficial effects against high blood pressure 
by modulating the RAAS in the cardio-renal syndrome. Thus, it should be considered an effective traditional medicine in hypertension treatment.

Keywords: renovascular hypertension; Gynura divaricata (L.) DC; renin-angiotensin-aldosterone system (RAAS); cardio-renal syndrome

\section{Introduction}

Cardiovascular dysfunction increases the incidence of heart failure, stroke, and hypertension. Fortunately, hypertension is known as the primary modifiable risk factor for cardiovascular disease [1,2]. Hypertension is associated with various diseases such as metabolic, renal, and endothelial dysfunctions [3]; it is responsible for sympathetic nerve activation, which, if excessive, causes various complications [4]. Endothelial cells are fundamental in blood circulation, vasoactive factor release, and vessel activation [5]. Nitric oxide is produced by nitric oxide synthase (NOS) in endothelial cells and is considered an important endothelium-derived relaxing factor. Reduced NO activity modifies endothelial status and also affects the cardiovascular system [6,7]. Reduced NO bioavailability could lead to cardiac and endothelial dysfunctions [8]. NO is also associated with kidney function by regulating glomerular ultrafiltration and medullary bloodstream $[9,10]$. Reactive oxygen species, produced by the impaired endothelin function, lead to a reduced NO availability [11]. Imbalanced NO production might impair mineralocorticoid functions or result in renal hypertension and cardiac dysfunction [12,13]. The two-kidney one-clip (2K1C) model used in this study is a classic renovascular hypertension model used in various experiments [14]. The renin-angiotensin-aldosterone system (RAAS) activation is crucial for the development and progression of hypertensive renal damage. The 2K1C model displays such hypertension due to the overactivation of the RAAS, leading to renal-heart damage [15]. The RAAS imbalance could lead to renovascular hypertension and several cardiovascular pathologies, as well as kidney dysfunction by increasing the angiotensin (Ang) II concentration and aldosterone level [16]. RAAS is an important regulator of renal blood flow, tubular sodium reabsorption, and Ang II activation. After the left kidney artery is clipped, the dysregulation of the RAAS triggers a sudden increase in Ang II concentration. Such an abnormal increase in the Ang II concentration results in the immoderate activation of the sympathetic nerves, functioning as a vasoconstrictor [17]. In addition, the $2 \mathrm{~K} 1 \mathrm{C}$ model is closely associated with NO production and increased oxidative stress, characterized by the presence of fibrosis, the deterioration of kidney structure and function [18,19], and subsequently, cardiac diseases [20]. Among the potential medicinal agents for hypertension, Gynura divaricata (L.) DC (Compositae) (GD), found in various parts of Asia, has long been used as a traditional medicine for hypertension and prescribed for diabetes treatment [21,22]. Several studies have shown that GD is associated with glucose metabolism and inhibits fat deposition in broilers [23,24]. In accretion, a similar plant, Gynura procumbens, has been reported to possess angiotensin-converting enzyme inhibitory activity [25]. However, no study has been conducted to evaluate the effects of GD extracts on a hypertensive rat model. Therefore, we aimed at investigating whether G. divaricata could ameliorate blood vessel dysfunction, kidney injury, or cardiac diseases in 2K1C rats and determining the G. divaricate-induced effector mechanisms in hypertension treatment.

\section{Material and Methods}

\subsection{Plant Material and Gynura divaricata Extract Preparation}

GD was purchased from the Misan Farm (Daegu, Korea) and boiled with $2 \mathrm{~L}$ of distilled water at $100{ }^{\circ} \mathrm{C}$ for $2 \mathrm{~h}$. The GD extract was filtered using a filter paper and centrifuged at $900 \times g$ at $4{ }^{\circ} \mathrm{C}$ for $20 \mathrm{~min}$, then the supernatant was incrassated in a rotary evaporator. We obtained $35.58 \mathrm{~g}$ of GD extract that we lyophilized using a freeze-drier and kept at $-70{ }^{\circ} \mathrm{C}$ until further use. 


\subsection{Major Metabolite Isolation and Structural Analysis}

The crude extract of GD (20.2 g) was suspended in distilled water (1000 mL) and successively partitioned with ethyl acetate and butanol $(\mathrm{BuOH})$. The $\mathrm{BuOH}$ fraction $(880 \mathrm{mg})$ was fractionated using reversed-phase $\mathrm{C} 18$ flash column chromatography $(46 \times 380 \mathrm{~mm})$, eluting with a stepwise gradient of $10,20,30,40,50,70$, and $100 \%(v / v)$ methanol $(\mathrm{MeOH})$ in water $(500 \mathrm{~mL}$ each) to produce seven consecutive fractions, GDB-1-7. The MWCB-2 subfraction was further purified by reversed-phase high-performance liquid chromatography using column YMC-Pack ODS-A (150 × $20 \mathrm{~mm})$ eluting with a gradient of $\mathrm{MeOH}$ in water $(0.1 \%$ formic acid, $10 \%$ to $40 \%$ in $20 \mathrm{~min})$ at a flow rate of $5 \mathrm{~mL} / \mathrm{min}$ with ultraviolet (UV) detection at $254 \mathrm{~nm}$ to produce GDB-2-3 (2.6 mg, tR = $19.8 \mathrm{~min}$ ) and GDB-2-4 (1.6 mg, tR = $21.2 \mathrm{~min}$ ) (Supplementary Figure S1).

\subsection{K1C Hypertensive Rat Model}

We used the previously reported 2K1C Goldblatt model to treat hypertension in this study [26]. Rats were anesthetized with intramuscular ketamine $(25 \mathrm{mg} / \mathrm{kg})$ and Rompun $(5 \mathrm{mg} / \mathrm{kg})$ treatments, We inserted a $0.2-\mathrm{mm}$-thick silver clip into the left renal artery to produce $2 \mathrm{~K} 1 \mathrm{C}$ hypertensive rats. All procedures were performed similar to those in case of the $2 \mathrm{~K} 1 \mathrm{C}$ rats in the control group, except for the silver clip application. On a weekly basis, we measured the body weight and tail-cuff systolic blood pressure (SBP), using tail-cuff plethysmography for the latter (MK2000; Muromachi Kikai, Tokyo, Japan), under optimal circumstances such as ambient temperature and quiet room. Measurements were performed at least determinations, and five-time averages were used for the experiment. The animals were divided into the following six experimental groups: control; $2 \mathrm{~K} 1 \mathrm{C}$ rats; $2 \mathrm{~K} 1 \mathrm{C}$ rats treated with olmetec (OMT, $10 \mathrm{mg} / \mathrm{kg} /$ day); and 2K1C rats treated with GD extracts at three different doses (50, 100, and $200 \mathrm{mg} / \mathrm{kg} /$ day) for 3 weeks by oral gavage. All groups were provided ad libitum with water and food (Cargill Agri Purina, Inc., Gunsan, Korea). Before being euthanized, six random rats in each group were individually housed in metabolic cages for 3 days (Tecniplast, Buguggiate, Italy). Their water and food intake were measured, and their urine samples were collected daily ( $24 \mathrm{~h})$ in a plastic flask. At the end of the experiments, the investigated animals were anesthetized with $4 \%$ isofluorane in an inhaler, before being euthanized. All rats were sacrificed using the guillotine method, and trunk blood was collected in pre-chilled ethylenediaminetetraacetic acid (EDTA)-coated or heparinized tubes. All animal experiments were performed under the National Institute of Health Guidelines for the Care and Use of Laboratory Animals. The animal procedures were approved by the Institutional Ethics Committee for Animal Experimentation of Wonkwang University (approval number WKU18-5).

\subsection{Aortic Tissue Immunohistochemistry}

The thoracic aorta was separated in the rats, and the fat was carefully removed from the aorta for the prevention of endothelin cell damage. The aorta was cut into roughly 3-mm-wide rings and the experiment was implemented in $\mathrm{O}_{2}$ mix-containing Krebs solution $(\mathrm{pH}=7.4)$. The relaxation response to acetylcholine $(\mathrm{ACh})$ was measured in the aortic tissue precontracted using phenylephrine $(\mathrm{PE}, 1 \mu \mathrm{M})$. The isometric tension changes were recorded using a transducer (GrassFT 03, Grass Instrument Co., Quincy, MA, USA). Poly-L-lysine-coated slides (Fisher Scientific, Pittsburgh, PA, USA) were used for immunohistochemical staining. Paraffin sections were stained using the Histostain ${ }^{\circledR}$-SP kit (Invitrogen) following the streptavidin-biotin labeling method. We used the Image analysis software Image-Pro Plus for quantitative analysis, measuring an average of 10-20 randomly selected areas.

\subsection{Aldosterone and Ang II Radioimmunoassay}

We used a commercial aldosterone assay kit (Aldoctk-2, DiaSorin Inc., Stillwater, MN, USA) to measure aldosterone levels and analyzed them by radioimmunoassay (RIA). The Ang II measurement was performed using a commercial Ang II assay kit (Phoenix Pharmaceuticals, Inc., Burlingame, CA, 
USA) and it was also analyzed by RIA. Aldosterone and Ang II results were expressed as picograms of Ang II per milliliter (pg/mL).

\subsection{Blood Analysis}

Blood samples were obtained in a test tube containing EDTA and subsequently centrifuged at $3000 \mathrm{rpm}$ for $20 \mathrm{~min}$ at $4{ }^{\circ} \mathrm{C}$. Plasma samples obtained for albumin, blood urea nitrogen (BUN), and creatinine level measurements were frozen at $-70{ }^{\circ} \mathrm{C}$ until further use and measured using a commercial kit (77184, Arkray, Japan).

\subsection{RNA Isolation and Quantitative Real-Time Polymerase Chain Reaction (Q-PCR) Analysis}

We used the RiboZol reagent (Amresco, Solon, OH, USA) for RNA extraction from the left atrium, right atrium, ventriculus sinister, and ventriculus dexter. We measured total RNA quantities by recording the absorbances of the samples at wavelengths of 260 and $280 \mathrm{~nm}$ using a UV spectrophotometer. Total RNA was reverse transcribed to cDNA using a High Capacity RNA-to-cDNA Kit (Applied Biosystems, Waltham, MA, USA). The Q-PCR analysis of the samples was performed using a Power SYBR Green PCR Master Mix (Applied Biosystems). The PCR primers used in this study are listed in Table 1. The gene expression levels were analyzed using a Step One Plus Real-Time PCR system (Applied Biosystems). The holding stage for gene amplification was started at $95^{\circ} \mathrm{C}$ for $10 \mathrm{~min}$ to activate the AmpliTaq enzyme, followed by 40 cycles of amplification at $95^{\circ} \mathrm{C}$ for $15 \mathrm{~s}$ (similar to denaturation), annealing, and extension at $60^{\circ} \mathrm{C}$ for $60 \mathrm{~s}$. The PCR product temperature was increased from $60{ }^{\circ} \mathrm{C}$ to $95^{\circ} \mathrm{C}$ at a rate of $0.3^{\circ} \mathrm{C} / \mathrm{s}$. The mRNA expression of each target gene was performed in triplicate and normalized to the endogenous glyceraldehyde 3-phosphate dehydrogenase (GAPDH).

Table 1. Primers used in the real-time polymerase chain reaction (Q-PCR).

\begin{tabular}{cr}
\hline Gene & \multicolumn{1}{c}{ Primer Nucleotide Sequence } \\
TNT & Forward: 5'-CGT GGC TTG GGT TTG GTG T-3' \\
& Reverse: 5'-AGA CTG GAG TGA AGA AGA GGA GGA C-3' \\
\hline \multirow{2}{*}{ BNP } & $\begin{array}{r}\text { Forward: } \\
\text { ('-TGA TTC CTG CTC CTG CTT TTC-3' } \\
\text { Reverse: 5'-GTG GAT TGT TCT GGA GAC TG-3' }\end{array}$ \\
\hline \multirow{2}{*}{ GAPDH } & Forward: 5'-CAG TGC CAG CCT CGT CTC-3' \\
& Reverse: 5'-AGG GGC CAT CCA CAG TCT-3'
\end{tabular}

\subsection{Statistical Analysis}

Bonferroni's multiple comparisons test was used to compare significant differences by repeated measures of analysis of variance (ANOVA). Furthermore, we also applied the Student's $t$-test for unpaired data. Statistical significance was defined as $p<0.05$. The results are presented as the mean \pm standard error (SE).

\section{Results}

\subsection{High-Performance Liquid Chromatography Analysis of GD}

GDB-2-3, GDB-2-4, GDB-4-1, and GDB-4-4 were identified as 2-propenoic acid, caffeic acid, dicaffeic acid, and kaempferol-3-O-rhamnoside, respectively, using ${ }^{1} \mathrm{H}$ and ${ }^{13} \mathrm{C}$ nuclear magnetic resonance (NMR) data analysis of the compounds and comparing our results with previously-reported data, as well as mass spectrum (MS) analysis in the case of GDB-4-1 and GDB-4-4 (Figure 1 and Supplementary Figure S1). 
<smiles>O=C(/C=C/c1ccc(O)c(O)c1)OC1CCC(O)C1O</smiles>

2-propenoic acid<smiles>O=C(/C=C/c1ccc(O)c(O)c1)OC1CC(O)(C(=O)O)CC(O)C1OC(=O)/C=C/c1ccc(O)c(O)c1</smiles>

4,5-di- $O$-caffeoylquinic acid<smiles>O=C(O)/C=C/c1ccc(O)c(O)c1</smiles>

caffeic acid<smiles>CC1OC(Oc2c(-c3ccc(O)cc3)oc3cc(O)cc(O)c3c2=O)C(O)C(O)C1O</smiles>

kaempferol-3- $O$-rhamnoside

Figure 1. Structural identification of compounds isolated from Gynura divaricata (L.) DC (GD) using HPLC.

\subsection{GD Effect on Systolic Blood Pressure and Vascular Tension}

We measured SBP in order to investigate how GD potentially affects it. The SBP of the control group and the 2K1C group were $105.2 \pm 3.93 \mathrm{mmHg}$ and $220.8 \pm 4.95 \mathrm{mmHg}$, respectively. The SBP of the $2 \mathrm{~K} 1 \mathrm{C}$ group was higher than that of the control group but the SBP significantly decreased in the GD treatment group (Figure 2).
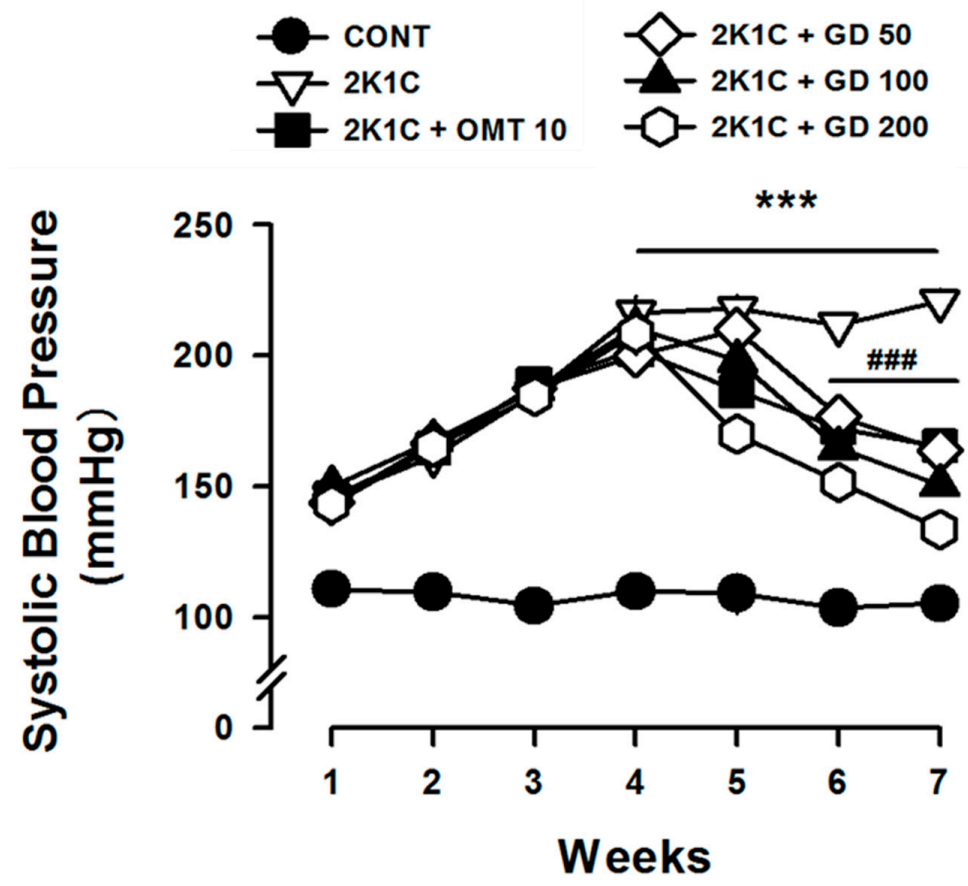

Figure 2. Effect of Gynura divaricata (L.) DC on systolic blood pressure (mmHg). The GD treatments at different concentrations (50, 100, $200 \mathrm{mg} / \mathrm{kg} /$ day) decreased systolic blood pressure (SBP) in 2K1C hypertensive rats. The values are expressed as the mean \pm standard error $\left(n=10\right.$ per group). ${ }^{* * *} p<0.001$, vs. CONT and ${ }^{\# \#} p<0.001$, vs. 2K1C. 2K1C, two-kidney one-clip. 


\subsection{Effects of GD on Vascular Responses}

The phenylephrine-pre-contracted aortic ring relaxation was $59.62 \pm 7.22 \%$ in the $2 \mathrm{~K} 1 \mathrm{C}$ group. However, the vasodilation \% changes after the acetylcholine treatment (Ach, $1 \mu \mathrm{M})$ were 76.46 \pm 5.46 , $86.26 \pm 5.19$, and $97.72 \pm 8.08 \%$ in the case of the GD 50, 100, and $200 \mathrm{mg} / \mathrm{kg} /$ day treatments, respectively. The vascular response to ACh was better restored in the GD treatment group than in the $2 \mathrm{~K} 1 \mathrm{C}$ group (Figure 3A). The vasodilation percentage (\%) response to the final concentrations of the ACh, sodium nitroprusside (SNP), and atrial natriuretic peptide (ANP) treatments are shown in Figure 3B-D. At the final SNP dose, the relaxation \% of the $2 \mathrm{~K} 1 \mathrm{C}$ group $\left(\mathrm{E}_{\max } 59.61 \pm 2.22, \log \mathrm{C}_{50}-7.79 \pm 0.09\right)$ was lower than that of the control group $\left(\mathrm{E}_{\max } 93.70 \pm 2.83, \log \mathrm{EC}_{50}-8.81 \pm 0.05\right)$. The relaxation $\%$ was higher in the 2K1C group treated with GD extracts at 100 and $200 \mathrm{mg} / \mathrm{kg} /$ day concentrations than in the 2K1C group. The maximal GD relaxation effect rates were $72.85 \pm 4.49,80.08 \pm 4.17$, and $76.4 \pm 4.07 \%$ in the case of GD extract concentrations of 50,100 , and $200 \mathrm{mg} / \mathrm{kg} / \mathrm{day}$, respectively, and $88.9 \pm 2.7 \%$ (OMT dose, $10 \mathrm{mg} / \mathrm{kg} /$ day) at $10 \mu \mathrm{M}$ ANP concentration. In contrast, the maximal relaxation rate was $54.64 \pm 7.28 \%$ at $10 \mu \mathrm{M}$ ANP concentration. The related statistical comparison of ACh, SNP, and ANP is shown in Supplementary Table S1. The vascular relaxation of the aorta ring was decreased to a greater degree in the $2 \mathrm{~K} 1 \mathrm{C}$ group than in the control group. The aortic ring relaxation in the GD treatment group was more relevant than that in the $2 \mathrm{~K} 1 \mathrm{C}$ group (Figure $3 \mathrm{~B}-\mathrm{D}$ ).

A
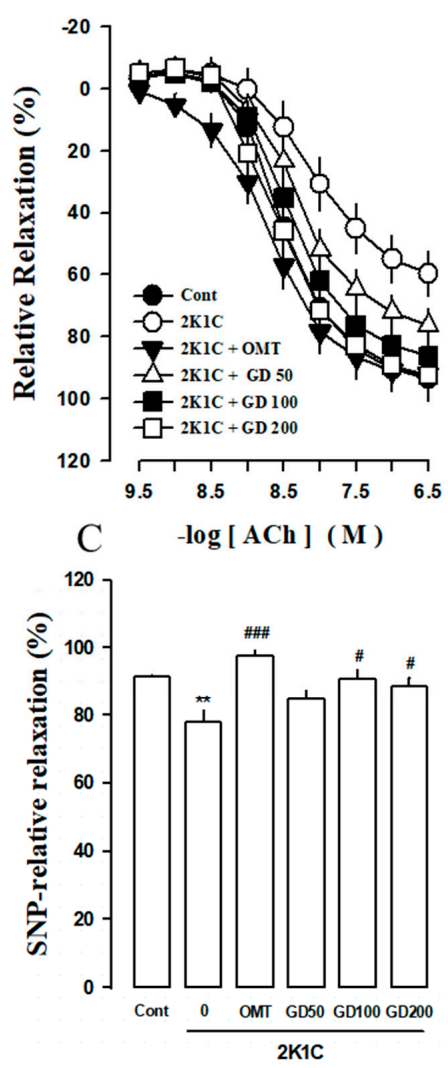

B
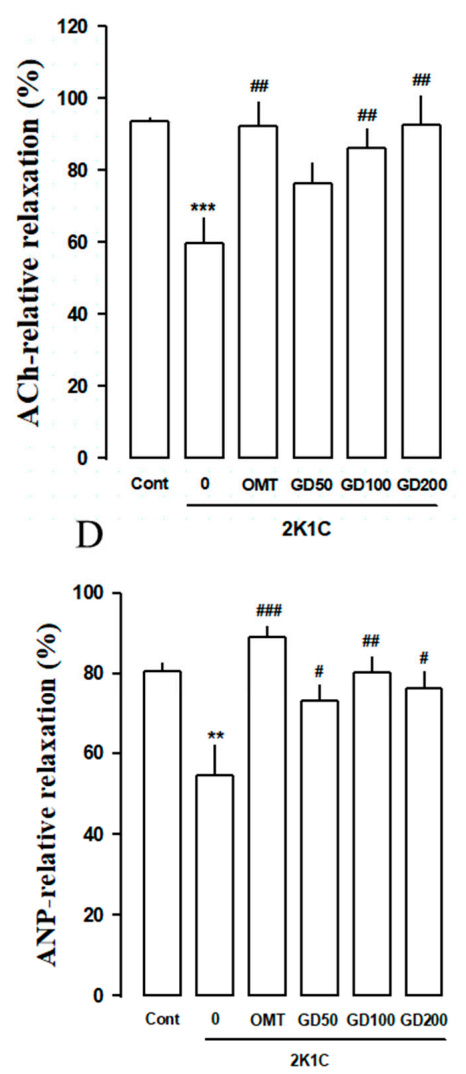

Figure 3. Vasorelaxation effect of Gynura divaricata (L.) DC (GD) following acetylcholine (ACh), sodium nitroprusside (SNP), and atrial natriuretic peptide (ANP) treatments. (A) Dose-response curves of ACh relaxation in the thoracic aorta of the 2K1C model; (B) The final ACh dose was changed in \% change expression with each group; (C) Dose-response curves of SNP relaxation in the thoracic aorta of the 2K1C model; (D) Effect of GD on the ANP relaxation of the 2K1C model. Responses are expressed as the percentage of relaxations relative to the PE-induced pre-contractions. Each value shows the mean \pm standard error $\left(n=10\right.$ per group). ${ }^{* *} p<0.01,{ }^{* * *} p<0.001$, vs. CONT and ${ }^{\#} p<0.05,{ }^{\# \#} p<0.01$, \#\#\# $p<0.0001$ vs. 2 K1C. 
3.4. Effects of GD on Endothelial Nitric Oxide Synthase (eNOS) and Endothelin-1 (ET-1) Immunoreactivity in the Thoracic Aorta

In the thoracic aorta, endothelial nitric oxide synthase (eNOS) expression was measured using immunohistochemistry. The eNOS expression was lower in the $2 \mathrm{~K} 1 \mathrm{C}$ group compared to the control. However, the GD treatment significantly increased eNOS expression (Figure 4A). In Figure 4B, a digitalized eNOS image values show that the group treated with the GD extract at a concentration of $200 \mathrm{mg} / \mathrm{kg} /$ day exhibited higher eNOS expression (0.9657) than the 2K1C group (0.2586). Moreover, endothelin-1 (ET-1) immunoreactivity levels were higher in the 2K1C group than in the control. However, the $2 \mathrm{~K} 1 \mathrm{C}$ group treated with the GD extracts exhibited significantly higher ET-1 immunoreactivity levels than the control (Figure $4 \mathrm{C}$ ). The digitalized ET-1 immunoreactivity was higher in the $2 \mathrm{~K} 1 \mathrm{C}$ group (2.7317) than in the control. However, the expression levels decreased in the group treated with the GD extract at a concentration of $200 \mathrm{mg} / \mathrm{kg} / \mathrm{day}$ (1.0976) compared with the 2K1C group (Figure 4D).

A

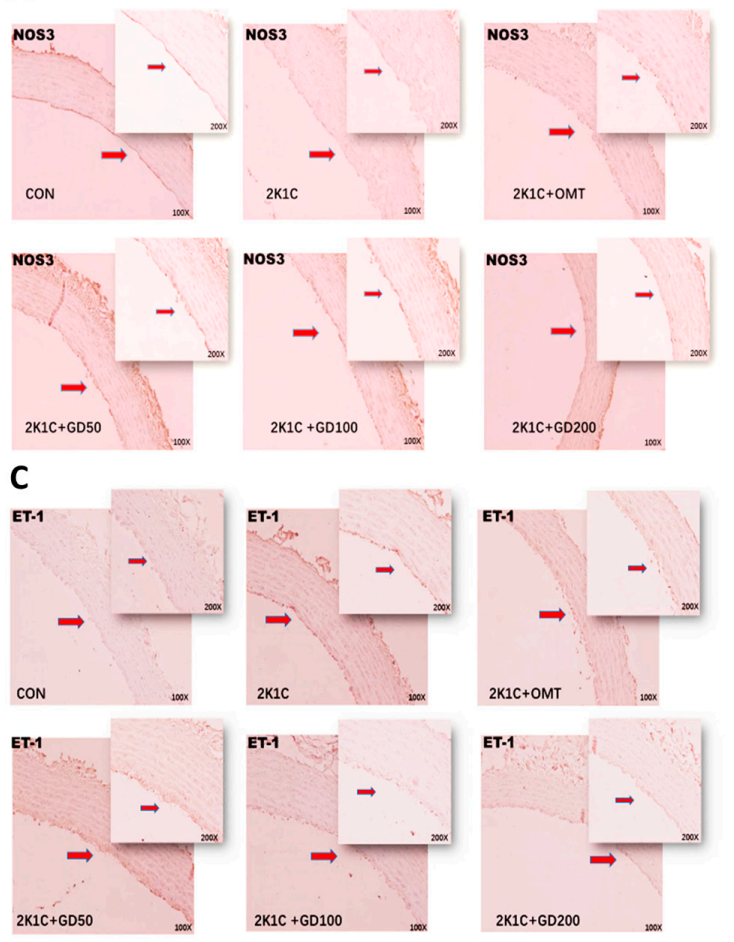

B
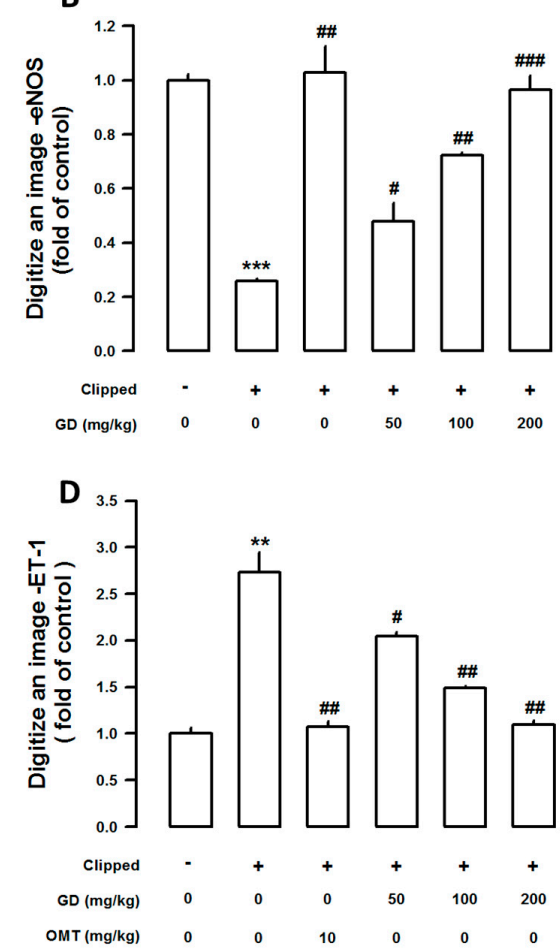

Figure 4. Effect of Gynura divaricata (L.) DC on endothelial nitric oxide synthase (eNOS) and endothelin-1 (ET-1) expressions in the blood vessels. (A) Immunohistochemical expression of eNOS in the aorta (magnification $\times 200$ ); (C) Immunohistochemical expression of ET-1 in the aorta. Quantitative analysis of eNOS (B) and ET-1 (D) area. ${ }^{* *} p<0.01,{ }^{* * *} p<0.001$, vs. CONT and ${ }^{\#} p<0.05,{ }^{\# \#} p<0.01$, \#\#\# $p<0.0001$ vs. $2 \mathrm{~K} 1 \mathrm{C}$.

\subsection{Effects of GD on the Cardiac Function}

In order to further clarify how GD might affect cardiac function, we measured the left ventricular weight, as well as brain natriuretic peptide (BNP) and troponin T (TnT) expression levels in GD-treated $2 \mathrm{~K} 1 \mathrm{C}$ rats. However, the ventricular weight/body weight ratios of the $2 \mathrm{~K} 1 \mathrm{C}$ group were significantly higher than those of the control group, and the GD groups showed significantly reduced ventricular weight/body weight ratios compared with those in the $2 \mathrm{~K} 1 \mathrm{C}$ group (Figure 5A,B). In order to investigate how GD might affect heart function, we measured the TnT and BNP expression levels, known as cardiac dysfunction biomarkers, in the left ventricle. The TnT and BNP mRNA levels were both higher in the $2 \mathrm{~K} 1 \mathrm{C}$ group than in the control group. The GD treatment suppressed the induction of these factors (Figure 6A,B). 

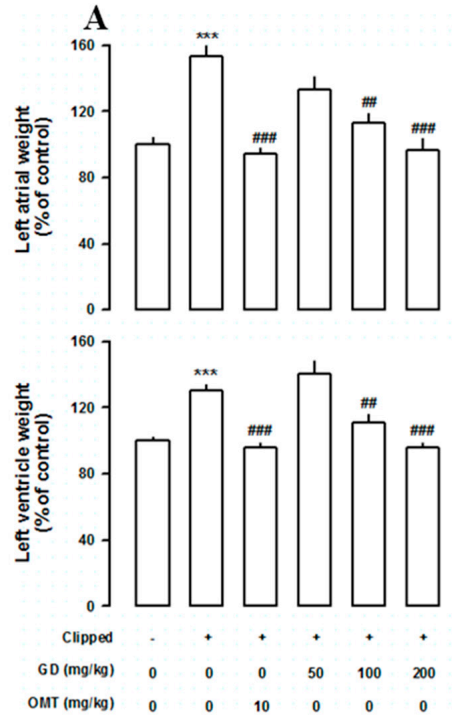

B
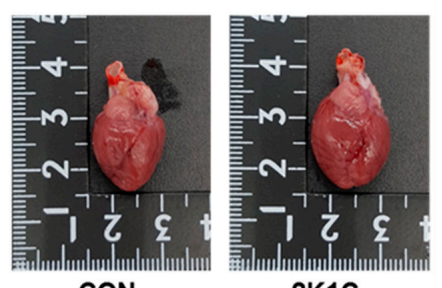

2K1C

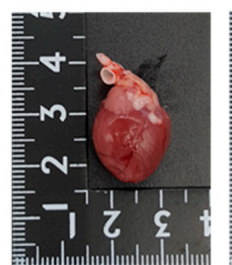

2K1C+GD50

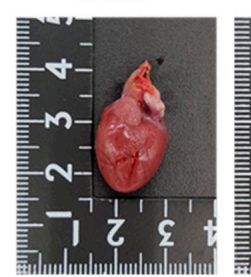

2K1C+GD100

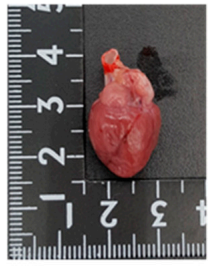

2K1C+OMT

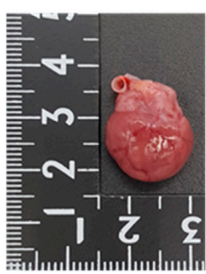

$2 \mathrm{~K} 1 \mathrm{C}+\mathrm{GD} 200$

Figure 5. Effects of Gynura divaricata (L.) DC (GD) on heart weight and shape. (A) Effects of GD on the left atrial and left ventricular weight (expressed as \% of control); (B) Photographs of the heart size in each group. Each value represents the mean \pm standard error $\left(n=10\right.$ per group). ${ }^{* *} p<0.001$ vs. CONT and ${ }^{\# \#} p<0.01,{ }^{\# \# \#} p<0.001$ vs. 2K1C.

A

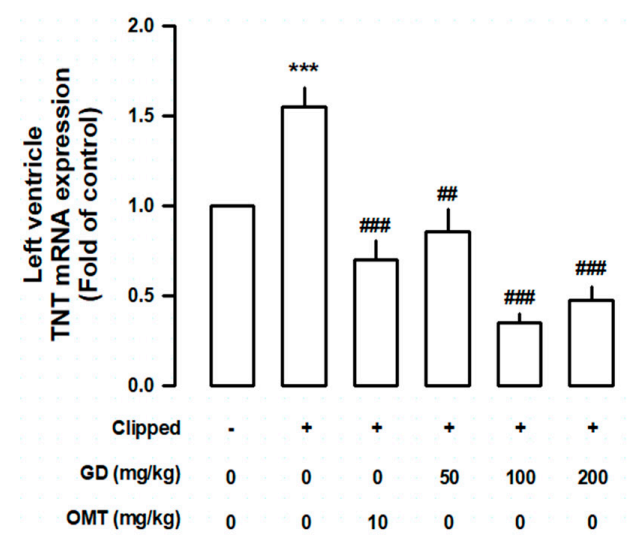

B

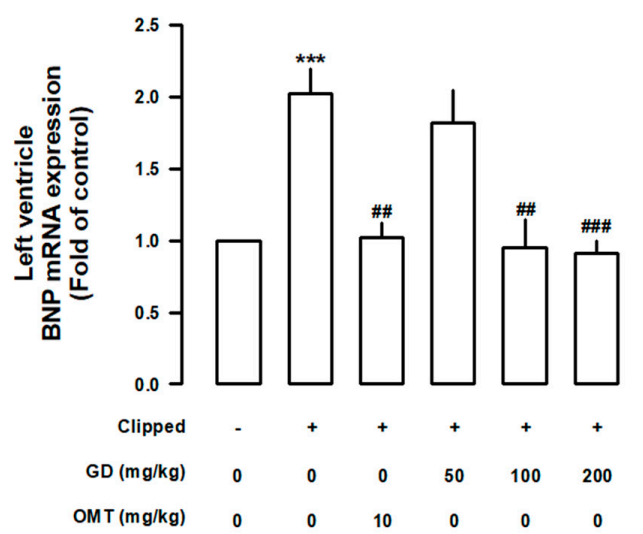

Figure 6. Effects of Gynura divaricata (L.) DC (GD) on the biomarkers on cardiac dysfunction. (A) Effects of GD on the expression of troponin T (TnT) mRNA. Real time quantitative polymerase chain reaction of TnT mRNA was performed from the left ventricle; (B) Effects of GD on the expression of brain natriuretic peptide mRNA. Each value shows the mean \pm standard error $\left(n=10\right.$ per group). ${ }^{* * *} p<0.001$, vs. CONT and ${ }^{\# \#} p<0.011^{\# \#} p<0.0001$ vs. $2 \mathrm{~K} 1 \mathrm{C}$.

\subsection{Effects of $G D$ on Renal Function}

Aldosterone, angiotensin, BUN, albumin, and creatinine clearance (Ccr) are generally considered as renal function biomarkers, we thus measured them to evaluate how GD might affect renal function in $2 \mathrm{~K} 1 \mathrm{C}$ rats. We observed that BUN and aldosterone levels, as well as angiotensin concentration, were significantly lower in the GD-treated group than those in the $2 \mathrm{~K} 1 \mathrm{C}$ group. In addition, the albumin and Ccr levels in the GD-treated groups were also significantly more upregulated than those in the control group (Table 2). The urinary volume was significantly higher in the $2 \mathrm{~K} 1 \mathrm{C}$ group than in the control group and it significantly decreased in the GD group (Table 3). The urinary sodium, chloride, and potassium excretion levels significantly decreased in the $2 \mathrm{~K} 1 \mathrm{C}$ group. The electrolyte excretion level was better restored in the GD groups than in the 2K1C group (Table 3). 
Table 2. Effects of the Gynura divaricata (L.) DC (GD) treatment on renal functional parameters.

\begin{tabular}{|c|c|c|c|c|c|c|}
\hline & CONT & $2 \mathrm{~K} 1 \mathrm{C}$ & $\begin{array}{c}\text { OMT } 10 \\
\text { (mg/kg/day) }\end{array}$ & $\begin{array}{c}\text { GD 50 } \\
\text { (mg/kg/day) }\end{array}$ & $\begin{array}{c}\text { GD 100 } \\
\text { (mg/kg/day) }\end{array}$ & $\begin{array}{c}\text { GD 200 } \\
\text { (mg/kg/day) }\end{array}$ \\
\hline Aldosterone $(\mathrm{pg} / \mathrm{mL})$ & $248.3 \pm 54.5$ & $1693 \pm 496.6^{* * *}$ & $253.1 \pm 46.3$ \#\#\# & $212.6 \pm 69.5$ \#\#\# & $108.4 \pm 13.6$ \#\#\# & $188 \pm 20^{\# \# \#}$ \\
\hline Angiotensin $(\mathrm{pg} / \mathrm{mL})$ & $532.1 \pm 36.8$ & $1699.8 \pm 144 * * *$ & $1168.6 \pm 88.1^{\#}$ & $1250.6 \pm 119.5^{\#}$ & $910 \pm 109$ \#\# & $623 \pm 112.6$ \#\# \\
\hline Albumin (g/dL) & $3.1 \pm 0.03$ & $2.5 \pm 0.06 * * *$ & $3.3 \pm 0.05$ & $3.1 \pm 0.05$ \#\#\# & $3.2 \pm 0.06^{\# \# \# ~}$ & $3.1 \pm 0.12 \# \#$ \\
\hline Bun $(\mathrm{mg} / \mathrm{dL})$ & $15.7 \pm 0.5$ & $38.6 \pm 7.9^{* *}$ & $16.5 \pm 0.7$ \# & $18.8 \pm 2.2 \#$ & $18.2 \pm 1.6 \#$ & $18.2 \pm 1.2^{\# \#}$ \\
\hline $\mathrm{Ccr}(\mathrm{mL} / \mathrm{min})$ & $527.9 \pm 143.2$ & $35.2 \pm 27.4 *$ & $466.7 \pm 100.1^{\# \#}$ & $426.9 \pm 63.7^{\#}$ & $399.8 \pm 100.6 \# \#$ & $487.9 \pm 92.2^{\# \#}$ \\
\hline
\end{tabular}

Table 3. Effects of the Gynura divaricata (L.) DC (GD) treatment on renal excretory function in 2K1C rats.

\begin{tabular}{|c|c|c|c|c|c|c|}
\hline & CONT & $2 \mathrm{~K} 1 \mathrm{C}$ & $\begin{array}{c}\text { OMT } 10 \\
\text { (mg/kg/day) }\end{array}$ & $\begin{array}{c}\text { GD 50 } \\
\text { (mg/kg/day) }\end{array}$ & $\begin{array}{c}\text { GD } 100 \\
\text { (mg/kg/day) }\end{array}$ & $\begin{array}{c}\text { GD 200 } \\
\text { (mg/kg/day) }\end{array}$ \\
\hline Body weight (g) & $458.6 \pm 3.4$ & $336.2 \pm 18.1^{* * *}$ & $415 \pm 7.3^{\# \#}$ & $418.7 \pm 6.3^{\# \#}$ & $414.3 \pm 3^{\# \#}$ & $423.1 \pm 7.8^{\# \#}$ \\
\hline Water intake (m/day) & $29.5 \pm 1.8$ & $61.5 \pm 6.3^{* * *}$ & $38.5 \pm 2.3 \# \#$ & $38.8 \pm 2.2 \ldots$ & $29.5 \pm 1.6$ \#\#\# & $30 \pm 2.7 \#$ \\
\hline Urine volume $(\mathrm{g} / 23 \mathrm{~h})$ & $11.3 \pm 0.8$ & $47.3 \pm 5.9 * * *$ & $19.8 \pm 2.6$ & $17 \pm 1.8^{\# \# \#}$ & $15.5 \pm 2$ & $15.6 \pm 1.4^{\# \# \# ~}$ \\
\hline Urine $\mathrm{Cl}^{-}(\mathrm{mmol} / \mathrm{L})$ & $274.5 \pm 22.7$ & $96 \pm 6.1^{* * *}$ & $208.2 \pm 36.5^{\#}$ & $222 \pm 15.4$ & $198.7 \pm 14.4$ & $273 \pm 31.1$ \\
\hline Urine $\mathrm{Na}^{+}(\mathrm{mmol} / \mathrm{L})$ & $165.7 \pm 19.2$ & $46.5 \pm 6.1^{* * *}$ & $124.8 \pm 19.3^{\# \#}$ & $133.8 \pm 11.9^{\# \# \# ~}$ & $108 \pm 10.6^{\# \#}$ & $120.6 \pm 23$ \\
\hline Urine $\mathrm{K}^{+}(\mathrm{mmol} / \mathrm{L})$ & $241.3 \pm 18$ & $78.3 \pm 7^{* * *}$ & $182.5 \pm 32.3^{\# \#}$ & $208.9 \pm 13.4$ & $186.7 \pm 14.4^{\# \# \#}$ & $201 \pm 24.7^{\# \# \#}$ \\
\hline Osmolality (mosm $/ \mathrm{kg})$ & $1786 \pm 111.1$ & $570.8 \pm 40.3^{* * *}$ & $1560.3 \pm 241.4$ & $1540.2 \pm 1.7 .6^{\# \#}$ & $1609 \pm 151.3$ & $1597.8 \pm 139.9 \#$ \\
\hline
\end{tabular}
vs. 2K1C.

\subsection{Effects of GD on Kidney Injury}

The weight of the left clipped kidney was markedly lower in the $2 \mathrm{~K} 1 \mathrm{C}$ group than that in the control group $(p<0.001)$. In contrast, the weight of the right non-clipped kidney in the 2K1C group was significantly higher than that in the control group $(p<0.001)$. The administration of the GD extract ( $200 \mathrm{mg} / \mathrm{kg} /$ day) improved kidney weight (Supplementary Figure S2). To determine how GD administration might affect tubular injury, we performed histological analysis. As shown by the PAS staining and density quantification, tubular damage could be observed in the $2 \mathrm{~K} 1 \mathrm{C}$ group. However, GD administration reduced fibrosis in the cortex (Figure 7), as well as in the inner (Figure 8) and outer medulla (Supplementary Figure S3).

A

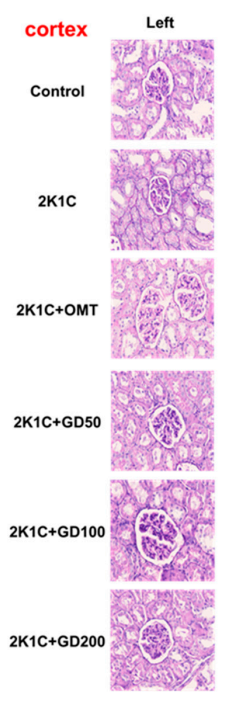

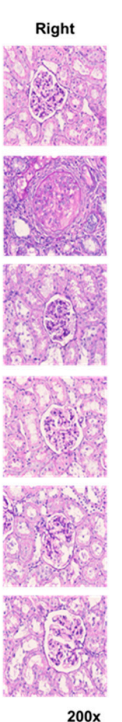

B

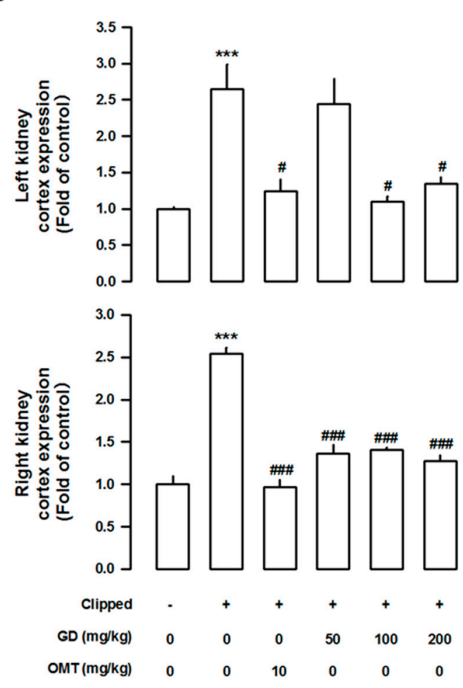

Figure 7. Effect of Gynura divaricata (L.) DC (GD) on fibrosis in the kidney tissue. (A) Periodic acid-Schiff (PAS) staining in the kidney cortex (magnification $\times 200$ ); (B) Quantitative assessments representing the results of five independent experiments. The values are expressed as the mean \pm standard error ( $n=5$ per group). ${ }^{* *} p<0.001$, vs. CONT and ${ }^{\#} p<0.05,{ }^{\# \# \#} p<0.0001$ vs. $2 \mathrm{~K} 1 \mathrm{C}$. 
A

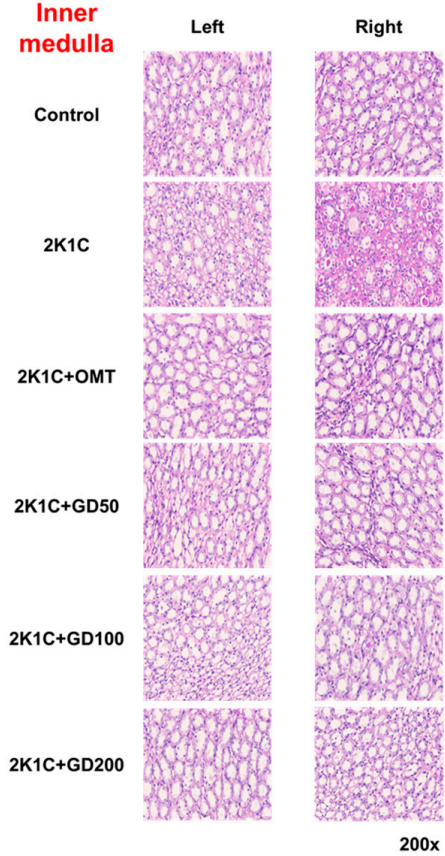

B

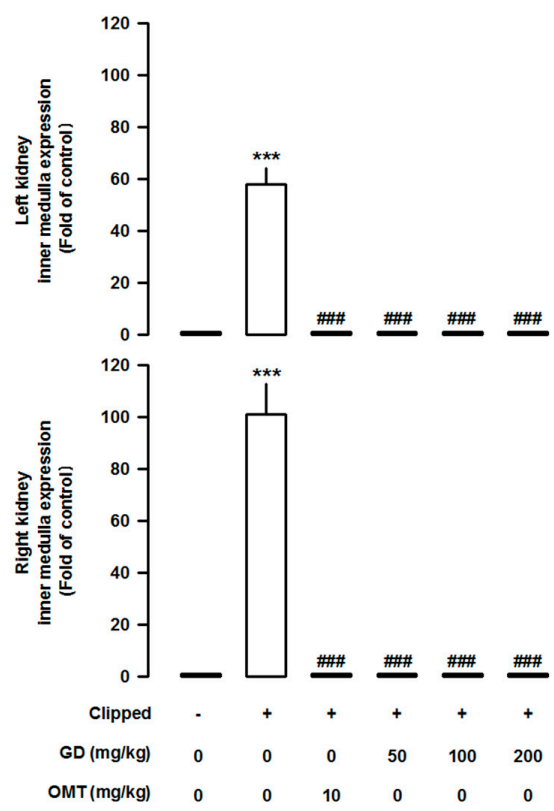

Figure 8. Effects of Gynura divaricata (L.) DC (GD) on kidney fibrosis in the outer medulla. (A) Periodic acid-Schiff staining of the kidney in the outer medulla. (magnification $\times 200$ ); (B) Quantitative assessments representing the results of five independent experiments. The values are expressed as the mean \pm standard error $\left(n=5\right.$ per group). ${ }^{* * *} p<0.001$, vs. CONT and ${ }^{\# \#} p<0.0001$ vs. $2 \mathrm{~K} 1 \mathrm{C}$.

\section{Discussion}

Hypertension is a critical modifiable cardiovascular disease risk factor in our society [27]. Increased blood pressure is a critical point of heart disease, stroke, coronary heart disease, and renal disease, leading to millions of deaths annually [28]. RAAS activation is crucial for the development and progression of hypertensive renal damage. $2 \mathrm{~K} 1 \mathrm{C}$ causes hypertension by RAAS overactivation and hypertension-induced renal-heart damage [14]. Therefore, this study aimed at determining whether renal function regulation, blood pressure, and the RAAS were affected by GD in 2K1C renal hypertensive rats. According to various studies, the RAAS is the main cause of cardiovascular disease-related hypertension and body fluid imbalance-related renal disease [14,15]. Cardio-renal syndrome (CRS) refers to a disease caused by the interaction between the kidneys and the cardiovascular system, where the acute or chronic dysfunction in one organ might induce acute or chronic dysfunction of the other. In this study, we used the 2K1C model, a CRS type 4 model, to determine whether GD exhibited a cardio-renal mutual improvement effect in 2K1C.

Renal hypertrophy, which is fundamental to hypertensive renal damage, is one of the hallmarks of pathological changes. Renal hypertrophy is also an early biomarker of renal dysfunction, which indicates the presence of glomerular hyperperfusion, hyperfiltration, and glomerular hypertension [29]. We observed systemic blood pressure increase in the $2 \mathrm{~K} 1 \mathrm{C}$ rats, directly associated with glomerular perfusion and pressure, thus leading to proteinuria glomerulosclerosis, interstitial renal fibrosis, and renal hyperfiltration [30]. In this study, osmolality and electrolytes were measured in the urine to investigate renal excretory function following the GD treatment. The renal excretory function, which was reduced in 2K1C hypertensive rats, was improved by GD. Therefore, we suggest that GD treatment improves renal function in $2 \mathrm{~K} 1 \mathrm{C}$.

With regard to vascular function, GD improved the acetylcholine-, sodium nitroprusside-, and atrial natriuretic peptide-induced impaired vascular dilation in the aorta in $2 \mathrm{~K} 1 \mathrm{C}$ rats. Endothelial dysfunction was first described in hypertension by the inhibition of $\mathrm{NO}$ activity. The vasorelaxation response to ACh was enhanced in the GD $(50,100,200 \mathrm{mg} / \mathrm{kg} /$ day) treatment groups; NO release 
occurred via the activation of specific endothelial receptors [31,32]. NO and endothelin-1 (ET-1) are endothelium-derived mediators that play essential roles in vascular homeostasis [33]. Moreover, ET-1 is a crucial vasoactive substance associated with pathophysiological conditions such as hypertension, ischemic heart disease, and congestive HF [34]. In this study, immunohistochemistry analysis of the thoracic aorta showed decreased ET-1 levels following the GD treatment in 2K1C rats. These results suggest that the GD-induced restoration of the ET-1 receptor expression might be, at least in part, related to the impaired vascular reactivity improvement and lowering of the high blood pressure.

Ang II is a biological substance of RAAS and plays a critical role in renal function, such as renal disease, renal injury, and fibrosis [35]. 2K1C is well-known to increase blood pressure and activate the RAAS [36]. Our results showed that it was decreased following the GD treatment. 2K1C also increases aldosterone and Ang II levels. In this study, the plasma levels of these markers decreased following GD treatment. These results suggest that GD improves renal dysfunction by inhibiting the activity of the RAAS system.

The heart and the kidneys are closely associated with each other; therefore, their primary disorders extend to secondary dysfunction or injury [37]. Primary chronic kidney disease (CKD), a CRS type 4 condition, reduces heart function, resulting in ventricular hypertrophy and cardiovascular dysfunction [38,39]. CRS type 4 biomarkers, such as BNP and TnT, are used to diagnose cardiovascular diseases in patients with CKD [40-42]. Moreover, increased BNP and TnT levels are clinically used as cardiovascular mortality biomarkers $[43,44]$. In this study, the BNP and TnT mRNA expression levels in the heart tissues of $2 \mathrm{~K} 1 \mathrm{C}$ rats showed that their levels were reduced by the GD treatment. This study showed that GD improved cardiovascular and renal dysfunction observed in the presented innovative hypertension model, highlighting the potential of GD as a therapeutic agent for hypertension. However, it is necessary to acknowledge and resolve the two major limitations of the present study. First, we only studied the effect of GD, i.e., amelioration of the hypertension in the 2K1C mouse model, and did not study the associated underlying mechanisms. Second, in this study, we could only speculate that GD exhibits a protective effect signal on the RAAS in 2K1C mice. Therefore, more experiments should be performed in future studies to confirm the effect of GD on improving cardio-renal dysfunction.

\section{Conclusions}

This study showed that GD improved cardiovascular and renal dysfunction in an innovative hypertension model and provided important results that support the therapeutic utility of GD in treating hypertension. These findings indicate that GD exerts beneficial effects against high blood pressure by modulating the RAAS of the cardio-renal syndrome. Thus, GD could be considered an effective traditional medicine for hypertension treatment.

Supplementary Materials: The following are available online at http://www.mdpi.com/2072-6643/12/11/3321/s1, Figure S1: High-performance liquid chromatography (HPLC) chromatograms of Gynura divaricata (L.) DC (GD). (A) GDa; (B) GDB2-3; (C) GDB2-3 with GDa; (D) GDB2-4; (E) GDB2-4 with GDa; (F) GDB4-1; (G) GDB4-1 with GDa; (H) GDB4-4; (I) GDB4-4 with GDa, Figure S2: Effects of Gynura divaricata (L.) DC (GD) on kidney weight and shape. (A) Effect of GD on the left and right kidney weight; (B) Kidney size. Each value shows the mean \pm standard error ( $n=10$ per group). ${ }^{* * *} p<0.001$, vs. CONT and ${ }^{\#} p<0.05,{ }^{\# \# \#} p<0.0001$ vs. 2 K1C, Figure S3: Effects of Gynura divaricata (L.) DC (GD) on kidney outer medullar fibrosis. (A) Periodic acid-Schiff staining of the kidney in the outer medulla (magnification $\times 200$ ); (B) Quantitative assessments, representing the results of five independent experiments. The values are expressed as the mean \pm standard error $\left(n=5\right.$ per group). ${ }^{* *} p<0.001$, vs. CONT and ${ }^{\#} p<0.05,{ }^{\# \#} p<0.0001$ vs. $2 \mathrm{~K} 1 \mathrm{C}$, Table S1: $\mathrm{EC}_{50}$ and $\mathrm{E}_{\max }$ values for ACh, SNP, and ANP-induced relaxation of the GD treatment in $2 \mathrm{~K} 1 \mathrm{C}$ rats.

Author Contributions: D.G.K. and H.Y.K., important discussion, comments; M.H.H., X.J.J., and H.Y.K., conceived the study and designed the experiments; H.C.O. prepared GD extract (material); H.Y.K., M.H.H., and J.J.Y. performed the experiments; M.H.H., X.J.J., and H.Y.K. analyzed the data; H.Y.K. and D.G.K. prepared the figures; M.H.H. and H.Y.K. wrote the main text; H.S.L., D.G.K., and Y.J.L. revised the manuscript. All authors have read and agreed to the published version of the manuscript.

Funding: This work was supported by the National Research Foundation of Korea (NRF) (NRF-2017R1A5A2015805) to D.G.K. and NRF-2019R1I1A3A01062432 to H.Y.K. 
Acknowledgments: The authors thank Sunryo Yang for her kind arrangements of our laboratory works in the present study.

Conflicts of Interest: The authors declare no conflict of interest.

\section{References}

1. Lacruz, M.E.; Kluttig, A.; Hartwig, S.; Loer, M.; Tiller, D.; Greiser, K.H.; Werdan, K.; Haerting, J. Prevalence and incidence of hypertension in the general adult population. Medicine 2015, 94, e952. [CrossRef]

2. Bloch, M.J. Worldwide prevalence of hypertension exceeds 1.3 billion. J. Am. Soc. Hypertens. 2016, 10, 753-754. [CrossRef] [PubMed]

3. Bolad, I.; Delafontaine, P. Endothelial dysfunction: Its role in hypertensive coronary disease. Curr. Opin. Cardiol. 2005, 20, 270-274. [CrossRef] [PubMed]

4. Robinson, A.T.; Babcock, M.C.; Watso, J.C.; Brian, M.S.; Migdal, K.U.; Wenner, M.M.; Farquhar, W.B. Relation between resting sympathetic outflow and vasoconstrictor responses to sympathetic nerve bursts: Sex differences in healthy young adults. Am. J. Physiol. Regul. Integr. Comp. Physiol. 2019, 316, $463-471$. [CrossRef]

5. Peramaiyan, R.; Thamaraiselvan, R.; Jayakumar, T.; Yutaka, N.; Dhanapal, S.; Gautam, S.; Ikuo, N. The Vascular Endothelium and Human Diseases. Int. J. Biol. Sci. 2013, 9, 1057-1069.

6. Tousoulis, D.; Kampoli, A.M.; Tentolouris, N.P.C.; Stefanadis, C. The role of nitric oxide on endothelial function. Curr. Vasc. Pharmacol. 2012, 10, 4-18. [CrossRef] [PubMed]

7. King, A.L.; Polhemus, D.J.; Bhushan, D.; Otsuka, H.; Kazuhisa, K.; Nicholson, C.K.; Bradley, J.M.; Islam, K.N.; Calvert, J.W.; Tao, Y.X. Hydrogen sulfide cytoprotective signaling is endothelial nitric oxide synthase-nitric oxide dependent. Proc. Natl. Acad. Sci. USA 2014, 111, 3182-3187. [CrossRef]

8. Mudau, M.; Genis, A.; Lochner, A.; Strijdom, H. Endothelial dysfunction: The early predictor of atherosclerosis. Cardiovasc. J. Afr. 2012, 23, 222-231. [CrossRef]

9. Natarajan, M.; Habib, S.; Reddick, R.J.; Delma, C.R.; Manickam, K.; Prihoda, T.J.; Wemer, S.L.; Mohan, S. Endothelial cell-specific overexpression of endothelial nitric oxide synthase in Ins2Akita mice exacerbates diabetic nephropathy. J. Diabetes Complicat. 2018, 33, 23-32. [CrossRef]

10. Zhang, J.Y.; Cao, X.X.; Wen, H.X.; Zang, H.Y. Correlation analysis of levels of inflammatory cytokines and nitric oxide in peripheral blood with urine proteins and renal function in patients with gestational hypertension. Exp. Ther. Med. 2019, 13, 657-662. [CrossRef]

11. Schulz, E.; Gori, T.; Münzel, T. Oxidative stress and endothelial dysfunction in hypertension. Hypertens. Res. 2011, 34, 665-673.

12. Hilde, J.M.; Skjørten, I.; Grøtta, O.J.; Hansteen, V.; Melsom, M.N.; Hisdal, J.; Humerfelt, S.; Steine, K. Right ventricular dysfunction and remodeling in chronic obstructive pulmonary disease without pulmonary hypertension. J. Am. Coll. Cardiol. 2013, 62, 1103-1111.

13. Vermeulen Windsant, I.C.; Wit, N.C.J.; Sertorio, J.T.C.; Bijnen, A.A.; Ganushchak, Y.M.; Heijmans, J.H.; Tanus-Santos, J.E.; Jacobs, M.J.; Maessen, J.G.; Buurman, W.A. Hemolysis during cardiac surgery is associated with increased intravascular nitric oxide consumption and perioperative kidney and intestinal tissue damage. Front. Physiol. 2014, 5, 340. [CrossRef] [PubMed]

14. Pijacka, W.; McBryde, F.D.; Marvar, P.J.; Lincevicius, G.S.; Abdala, A.P.L.; Woodward, L.; Li, D.; Paterson, D.J.; Paton, J.F.R. Carotid sinus denervation ameliorates renovascular hypertension in adult Wistar rats. J. Physiol. 2016, 594, 6255-6266. [CrossRef] [PubMed]

15. Natalin, H.M.; Garcia, A.F.E.; Ramalho, L.N.Z.; Restini, C.B.A. Resveratrol improves vasoprotective effects of captopril on aortic remodeling and fibrosis triggered by renovascular hypertension. Cardiovasc. Pathol. 2016, 25, 116-119. [CrossRef] [PubMed]

16. Zhu, X.; Zhou, Z.; Zhang, Q.; Cai, W.; Zhou, Y.; Sun, H.; Qiu, L. Vaccarin administration ameliorates hypertension and cardiovascular remodeling in renovascular hypertensive rats. J. Cell. Biochem. 2018, 119, 926-937. [CrossRef]

17. Guimarães, D.D.; Cruz, J.C.; Carvalho-Galvão, A.; Zhuge, Z.; Marques, S.M.; Naves, L.M.; Persson, A.E.G.; Weitzberg, E.; Lundberg, J.O.; Balarini, C.M. Dietary nitrate reduces blood pressure in rats with angiotensin II-induced hypertension via mechanisms that involve reduction of sympathetic hyperactivity. Hypertension 2019, 73, 839-848. [CrossRef] 
18. Yu, T.T.; Guo, K.; Chen, H.C.; Lan, C.Z.; Wang, J.; Huang, L.L.; Wang, X.H. Effects of traditional Chinese medicine Xin-Ji-Er-Kang formula on 2K1C hypertensive rats: Role of oxidative stress and endothelial dysfunction. BMC Complement. Altern. Med. 2013, 13, 173. [CrossRef]

19. Alam, M.A.; Chowdhury, M.R.H.; Jain, P.; Sagor, M.A.T.; Reza, H.M. DPP-4 inhibitor sitagliptin prevents inflammation and oxidative stress of heart and kidney in two kidney and one clip (2K1C) rats. Diabetol. Metab. Syndr. 2015, 7, 107. [CrossRef]

20. Campagnaro, B.P.; Gava, A.L.; Meyrelles, S.S.; Vasquez, E.C. Cardiac-autonomic imbalance and baroreflex dysfunction in the renovascular angiotensin-dependent hypertensive mouse. Int. J. Hypertens. 2012, 968123. [CrossRef]

21. Li, J.; Feng, J.; Wei, H.; Liu, Q.; Yang, T.; Hou, S.; Zhao, Y.; Zhang, B.; Yang, C. The aqueous extract of Gynura divaricata (L.) DC improves glucose and lipid metabolism and ameliorates type 2 diabetes mellitus. Evid. Based Complement. Alternat. Med. 2018, 2018, 8686297. [CrossRef] [PubMed]

22. Wu, T.; Zhou, X.; Deng, Y.; Jing, Q.; Li, M.; Yuan, L. In vitro studies of Gynura divaricata (L.) DC extracts as inhibitors of key enzymes relevant for type 2 diabetes and hypertension. J. Ethnopharmacol. 2011, 136, 305-308. [CrossRef] [PubMed]

23. Xu, B.Q.; Zhang, U.Q. Bioactive components of Gynura divaricate and its potential use in health, food and medicine: A mini-review. Afr. J. Tradit. Complement. Altern. Med. 2017, 14, 113-127. [PubMed]

24. Jamjang, C.; Kijpakorn, S.; Angkanaporn, K. Effect of dietary inclusion of Gynura divaricate (L.) on growth performance, hematology, and carcass fat deposition in broilers. J. Poult. Sci. 2020, 57, 114-123.

25. Hoe, S.Z.; Kamaruddin, M.H.; Lam, S.K. Inhibition of angiotensin-converting enzyme activity by partially purified fraction of Gynura procumbens in spontaneously hypertensive rats. Med. Princ. Pract. 2007, 16, 203-208. [CrossRef] [PubMed]

26. Unger, T.; Borghi, C.; Charchar, F.; Khan, N.A.; Poulter, N.R.; Prabhakaran, D.; Ramirez, A.; Schlaich, M.; Stergiou, G.S.; Tomaszewski, M. International Society of Hypertension Global Hypertension Practice Guidelines. J. Hypertens. 2020, 75, 1334-1357.

27. Kitt, J.; Fox, R.; Tucker, K.L.; McManus, R.J. New approaches in hypertension management: A review of current and developing technologies and their potential impact on hypertension care. Curr. Hypertens. Rep. 2019, 21, 44. [CrossRef]

28. Fuchs, F.D.; Whelton, P.K. High blood pressure and cardiovascular disease. Hypertension 2020, 75, $285-292$. [CrossRef]

29. Bak, M.; Thomsen, K.; Christiansen, T.; Flyvbjerg, A. Renal enlargement precedes renal hyperfiltration in early experimental diabetes in rats. J. Am. Soc. Nephrol. 2000, 11, 1287-1292.

30. Flammer, A.J.; Anderson, T.; Celermajer, D.S.; Creager, M.A.; Deanfield, J.; Ganz, P.; Hamburg, N.M.; Lüscher, T.F.; Shechter, M.; Taddei, S. The assessment of endothelial function-from research into clinical practice. Circulation 2012, 126, 753-767. [CrossRef]

31. Nagasu, H.; Satoh, M.; Kidokoro, K.; Nishi, Y.; Channon, K.M.; Sasaki, T.; Kashihara, N. Endothelial dysfunction promotes the transition from compensatory renal hypertrophy to kidney injury after unilateral nephrectomy in mice. Am. J. Physiol. Renal Physiol. 2012, 302, 1402-1408. [CrossRef]

32. Zuccolo, E.; Lim, D.; Kheder, D.A.; Perna, A.; Catarsi, P.; Botta, L.; Rosti, V.; Riboni, L.; Sancini, G.; Tanzi, F. Acetylcholine induces intracellular $\mathrm{Ca}^{2+}$ oscillations and nitric oxide release in mouse brain endothelial cells. Cell Calcium 2017, 66, 33-47. [CrossRef] [PubMed]

33. Sánchez, A.; Martínez, P.; Muñoz, M.; Benedito, S.; García-Sacristán, A.; Hernández, M.; Prieto, D. Endothelin-1 contributes to endothelial dysfunction and enhanced vasoconstriction through augmented superoxide production in penile arteries from insulin-resistant obese rats: Role of ETA and ETB receptors. Br. J. Pharmacol. 2014, 171, 5682-5695. [CrossRef]

34. Adiarto, S.; Heiden, S.; Vignon-Zellweger, N.; Nakayama, K.; Yagi, K.; Yanagisawa, M.; Emoto, N. ET-1 from endothelial cells is required for complete angiotensin II-induced cardiac fibrosis and hypertrophy. Life Sci. 2012, 91, 651-657. [CrossRef]

35. Te Riet, L.; Van Esch, J.H.; Roks, A.J.; Van den Meiracker, A.H.; Danser, A.H. Hypertension: Renin-angiotensin-aldosterone system alterations. Circ. Res. 2015, 116, 960-975. [CrossRef] [PubMed]

36. Huang, L.L.; Pan, C.; Yu, T.T.; Guo, K.; Wang, X.H.; Zhang, J.Y.; Wang, H.Z.; Gao, S. Beneficial therapeutic effect of Chinese herbal Xinji'Erkang formula on hypertension-induced renal injury in the 2-kidney-1-clip hypertensive rats. Arf. J. Tradit. Complement. Altern. Med. 2014, 11, 16-27. [CrossRef] 
37. Ronco, C.; Di Lullo, L. Cardiorenal syndrome. Heart Fail. Clin. 2014, 10, 251-280. [CrossRef] [PubMed]

38. House, A.A. Cardio-renal syndrome type 4: Epidemiology, pathophysiology and treatment. Semin. Nephrol. 2012, 32, 40-48. [CrossRef]

39. Guo, K.; Lan, C.Z.; Yu, T.T.; Huang, L.L.; Wang, X.H.; Pan, C.; Gao, S. Effects of Xin-Ji-Er-Kang formula on 2K1C-induced hypertension and cardiovascular remodeling in rats. J. Ethnopharmacol. 2014, 155, 1227-1235. [CrossRef]

40. Marra, A.M.; Bossone, E.; Salzano, A.; D'Assante, R.; Monaco, F.; Ferrara, F.; Arcopinto, M.; Vriz, O.; Suzuki, T.; Cittadini, A. Biomarkers in pulmonary hypertension. Heart Fail. Clin. 2018, 14, 393-402. [CrossRef]

41. Yamashita, T.; Seino, Y.; Ogawa, A.; Ogata, K.I.; Fukushima, M.; Tanaka, K.; Mizuno, K. N-terminal pro-BNP is a novel biomarker for integrated cardio-renal burden and early risk stratification in patients admitted for cardiac emergency. J. Cardiol. 2010, 55, 377-383. [CrossRef] [PubMed]

42. Pokharel, Y.; Sun, W.; De Lemos, J.A.; Taffet, G.E.; Virani, S.S.; Ndumele, C.E.; Mosley, T.H.; Hoogeveen, R.C.; Coresh, J.; Wright, J.D. High sensitivity troponin T and cardiovascular events in systolic blood pressure categories: Atherosclerosis risk in communities study. Hypertension 2015, 65, 78-84. [CrossRef] [PubMed]

43. Choudhary, R.; Gopal, D.; Kipper, B.A.; Landa, A.D.L.P.; Aramin, H.; Lee, E.; Shah, S.; Maisel, A.S. Cardiorenal biomarkers in acute heart failure. J. Geriatr. Cardiol. 2012, 9, 292-304. [PubMed]

44. Cruz, D.N.; Fard, A.; Clementi, A.; Ronco, C.; Maisel, A. Role of biomarkers in the diagnosis and management of cardio-renal syndromes. Semin. Nephrol. 2011, 32, 79-92. [CrossRef]

Publisher's Note: MDPI stays neutral with regard to jurisdictional claims in published maps and institutional affiliations.

(C) 2020 by the authors. Licensee MDPI, Basel, Switzerland. This article is an open access article distributed under the terms and conditions of the Creative Commons Attribution (CC BY) license (http://creativecommons.org/licenses/by/4.0/). 